\title{
TRANSTORNO DE ESTRESSE PÓS-TRAUMÁTICO COMO DESENCADEADOR DE MUDANÇAS EPIGENÉTICAS NO CORPO
}

\section{ARTIGO DE REVISÃO}

REIS, Ariadna Jihani Damasceno Vidal de Santana ${ }^{1}$

ANJOS, Maria Clara Mota Nobre dos ${ }^{2}$

CAVALCANTI, Bruna Luiza de Mendonça ${ }^{3}$

SANTOS, Ketully Stefane Chaves dos ${ }^{4}$

DINIZ, Maria Celeste Campello ${ }^{5}$

REIS, Ariadna Jihani Damasceno Vidal de Santana. Et al. Transtorno de estresse pós-traumático como desencadeador de mudanças epigenéticas no corpo. Revista Científica Multidisciplinar Núcleo do Conhecimento. Ano 05, Ed. 08, Vol. 04, pp. 96-114. Agosto de 2020. ISSN: 2448-0959, Link de acesso: https://www.nucleodoconhecimento.com.br/saude/mudancas-epigeneticas

\section{RESUMO}

O transtorno de estresse pós-traumático (TEPT) tem por definição diagnóstica a ocorrência de um grave estresse traumático como fator etiológico desencadeante, sendo que após a exposição a esse evento traumático inicia-se uma série variável de

\footnotetext{
${ }^{1}$ Acadêmica do Curso de Medicina do Centro Universitário Tiradentes (UNIT-AL).

${ }^{2}$ Acadêmica do Curso de Medicina do Centro Universitário Tiradentes (UNIT-AL).

${ }^{3}$ Acadêmica do Curso de Medicina do Centro Universitário Tiradentes (UNIT-AL).

${ }^{4}$ Acadêmica do Curso de Medicina do Centro Universitário Maurício de Nassau (UNINASSAU).

5 Docente, Mestre, Professora Assistente do Curso de Medicina do Centro Universitário Tiradentes (UNIT-AL).
} 
sintomas característicos e perturbações de natureza psicológicas, sociais e biológicas. Este artigo avalia sistematicamente como o TEPT pode influenciar no eixo hipotálamopituitária-adrenal por modificações epigenéticas que suprimem ou estimulam a expressão genética de determinado gene através de biomarcadores. Pesquisa de abordagem qualitativa, com natureza do tipo revisão bibliográfica sistemática de caráter analítico. Foram pesquisados trabalhos que buscaram correlacionar o TEPT com alterações epigenéticas nas gerações seguintes. A pesquisa foi construída através de consultas a bancos de dados do NCBI: PubMed, BVS e Scielo. As informações foram coletadas de 14 artigos científicos publicados entre 2009 a 2018, e os idiomas foram delimitados a português e inglês. Foi observado que o TEPT é responsável por uma considerável modificação nos níveis de cortisol, serotonina e a sensibilidade para receptores de glicocorticoides. A revisão possibilitou a construção de uma síntese do conhecimento científico sobre a associação entre mudanças epigenéticas motivadas pelo TEPT em pacientes no material genético e tais modificações desses genes vão ser transferidas para as futuras gerações.

Palavras-chave: Metilação de DNA, epigenética, biomarcadores, transtornos de estresse pós-traumáticos.

\section{INTRODUÇÃO}

O transtorno de estresse pós-traumático (TEPT) define-se como um conjunto de sinais e sintomas psíquicos, físicos e emocionais que causam um distúrbio de ansiedade. $O$ TEPT é responsável por uma considerável modificação nos níveis de cortisol, serotonina e a sensibilidade para receptores de glicocorticoides (RGs). Assim, se desenvolve no indivíduo que foi vítima ou testemunha de uma situação traumática que apresentou ameaça a sua integridade ou a de pessoas ao seu redor. Esse distúrbio causa alterações hormonais ligadas ao eixo hipotálamo-pituitária-adrenal (HPA) e na expressão de determinados gene (VUKOJEVIC et al., 2014). Nesse ínterim, a relação entre o estresse, TEPT, e a epigenética torna-se nítida, pois, mesmo que não envolva mudança propriamente dita na sequência do código genético, há alterações que podem efetivar a estimulação ou inibição da expressão gênica de determinada informação. Tais alterações são a metilação do ácido desoxirribonucleico (DNA) e as 
modificações nas histonas que apresentam o papel do desenvolvimento normal e são cruciais para o desempenho da programação correta da expressão dos genes.

Neste artigo, será abordado principalmente o processo da metilação do DNA dos principais genes de RGs, mineralocorticoides (MR) e serotonina (HTR3A) que promove uma adaptação ao organismo e influência na susceptibilidade a doenças que consequentemente seriam também propagadas as próximas gerações.

Os genes HTR3A, NR3C1, NR3C2 e FKBP5 receberão enfoque neste artigo. Primeiramente, a hipermetilação do gene NR3C1 que resulta em sua baixa expressão e diminuição dos níveis de cortisol. O NR3C2 é responsável pela queda dos níveis de MR e, consequentemente, pela diminuição da quantidade de corticotropina. Esse processo ocorre através da metilação do gene que expressa o NR3C2 (PERROUD, 2014) O HTR3A pode estar associado à modificação nas estruturas cerebrais centrais ao processamento de emoções, principalmente quando essas estruturas são expostas ao estresse. Destaca-se, ainda, a influência em potencial do sistema serotoninérgico na fisiopatologia dos transtornos afetivos, como o TEPT. Por fim, o FKBP5, que atua como uma co-chaperona, modulando a atividade dos $R G$ em resposta a estressores na gestação e está relacionado também a exposição ao trauma gera a possibilidade da criança já nascer com mecanismo mais adaptado e propenso a desenvolver depressão e TEPT (PAQUETTE et al., 2014); (SCHECHTER et al., 2016).

\subsection{EPIGENÉTICA}

O termo epigenética significa "em adição à informação genética codificada no DNA" e é genericamente utilizado para definir mudanças que ocorrem na expressão gênica sem, no entanto, ocorrer nenhuma alteração na sequência do código genético (COSTA et al., 2013).

Alguns mecanismos epigenéticos incluem a metilação do DNA, o imprinting, mudanças na conformação da cromatina e o silenciamento mediado por RNA. A metilação do DNA é a modificação epigenética mais utilizada pela maior parte dos seres vivos como um agente de regulação da expressão gênica, podendo 
caracterizar-se como um fator de silenciamento do gene. Consiste na adição de um radical metil $(\mathrm{CH} 3)$ ao carbono 5 de Citosina, geralmente seguida por Guanina (dinucleotídeo $\mathrm{CpG}$ ), catalisada por enzimas DNA metiltransferases (DNMTs) (COSTA et al., 2013); (AMLI et al., 2016).

Figura 01. Metilação da citocina.

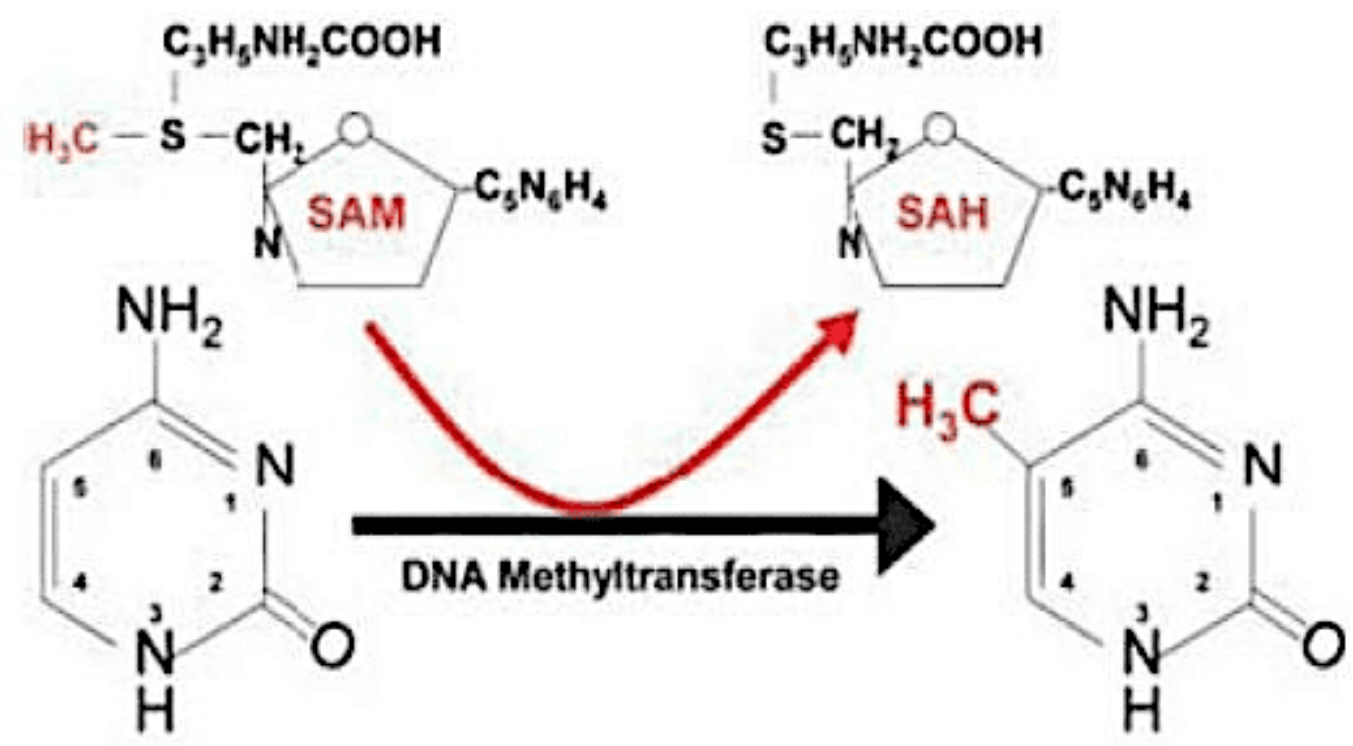

Cytosine

5-Methylcytosine

Fonte: CMLA. Cell. Mol. Life Sci 59 (2002) 241-257

\subsection{REGULAÇÃO DO EIXO HPA}

A atividade do eixo HPA é governada pela secreção de HLC - hormônio liberador de corticotrofina e vasopressina (AVP) - pelo hipotálamo, o qual, por sua vez, ativa a secreção do hormônio adrenocorticotrófico (ACTH) pela hipófise, que, finalmente, estimula a secreção de glicocorticóides pelo córtex adrenal. Nessa visão, os glicocorticóides interagem com seus receptores em múltiplos tecidos-alvo, incluindo o próprio eixo HPA, onde são responsáveis pela inibição feedback negativo da secreção do ACTH pela pituitária e do HLC, a partir do hipotálamo (JURUENA et al., 2004).

Embora os glicocorticóides ajustem as funções de quase todos os tecidos do corpo, o efeito fisiológico mais conhecido desses hormônios é a regulação do metabolismo 
energético. Nesse contexto, vários fatores controlam a atividade do eixo HPA. Além disso, há evidência de inervação direta catecolaminérgica, serotoninérgica e dopaminérgica nos neurônios produtores de HLC no hipotálamo e esses e outros neurotransmissores parecem influenciar a liberação de HLC. Por exemplo, a serotonina exerce uma influência estimuladora no HLC por meio dos subtipos de receptores 5-HT1A, 5-HT1B, 5-HT1C e 5-HT2. A norepinefrina possui um efeito mais variável, sendo estimulatória em doses baixas (via receptores alpha 1) e inibitória em doses altas (via receptores beta) (JURUENA et al., 2004).

Neste artigo, objetivou-se descobrir a relação epigenética de expressão dos genes no TEPT através dos biomarcadores supracitados. A partir do estudo destes, investigouse a sua interação com a regulação e atuação no eixo hipotálamo-hipófise-adrenal. Por fim, buscou-se entender como tais alterações vão atuar na transferência desses genes para as futuras gerações.

\section{METODOLOGIA}

A pesquisa desenvolveu-se com uma abordagem qualitativa, a qual se justifica por permitir o desvelamento do mundo pesquisado com aprofundamento dos dados científicos, o que possibilita uma melhor compreensão e análise do objeto da pesquisa. A natureza do estudo consistiu-se em uma revisão bibliográfica sistemática de caráter analítico. Justificando-se por auxiliar em uma construção de uma análise ampla da literatura, contribuindo como reflexão para a realização de futuros estudos. Delimitou-se o viés com os descritores estresse e epigenética. Utilizou-se para consulta em Biblioteca Virtual, bases de dados virtuais como: Lilacs, biblioteca virtual em saúde (BVS), Scielo e MEDLINE via Pubmed um total de 77.937 artigos que foram submetidos a uma nova revisão conduzida pela leitura dos títulos que também permitiu um critério de inclusão que seria o artigo tratar do TEPT; essa triagem preliminar excluiu 76.359 artigos.

Através da leitura do título sob o critério de estar relacionado ao TEPT. Esses filtros reduziram o número de artigos de cerca de 80 mil para 1.578 artigos. Tal sistematização de como foi realizada a pesquisa está definida na figura 02. 
A nova etapa da especificação temática contou a inserção de novos critérios de inclusão e exclusão, tais como: raça humana, mulheres, publicações de até 5 anos, exclusão de artigos revisão, com faixa etária entre 19-44 anos. Os 89 artigos resultantes dessa filtragem, passaram por uma análise na qual houve a remoção dos artigos duplicados aliados aos critérios de exclusão e inclusão, decrescendo o número de artigos para 14 artigos que foram submetidos a mais uma análise que envolveu a leitura desses artigos para que o grupo pudesse selecionar o que mais seria relevante para uma revisão.

Houve um enfoque em artigos sobre as vítimas de desastres, genocídios ou eventos traumáticos de grande escala que, por conseguinte, culminaram na exclusão os artigos que abordavam o tema, mas não correspondiam aos nossos objetivos para a escrita desse artigo de revisão, apenas oito artigos com utilidade para o recorte temático escolhido pelo grupo. Os artigos escolhidos foram organizados e representados no Quadro 01. 
Figura 02. Fluxograma demonstrando a forma que foi realizada a linha de exclusão da revisão sistemática

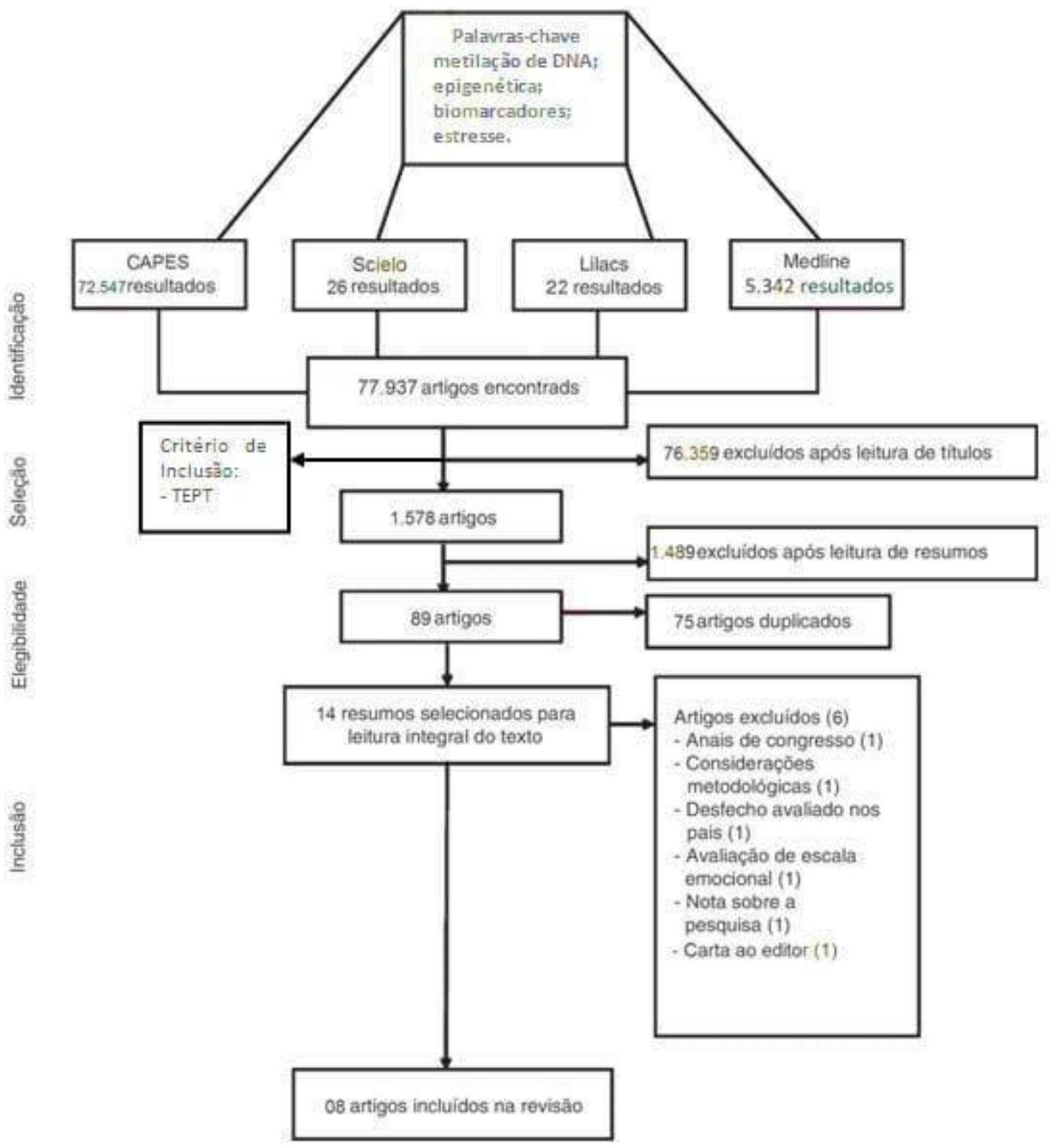

Fonte: Autores da pesquisa (2019).

Quadro 01 Relação de autores e seus respectivos artigos e a apresentação dos resultados encontrados.

\begin{tabular}{|l|l|l|l|l|}
\hline Autor & Artigos & Estudo & Objetivos & Resultados \\
\hline
\end{tabular}




\begin{tabular}{|c|c|c|c|c|}
\hline $\begin{array}{l}\text { McNerney, } \\
M W \text { et al } \\
(2018)^{8}\end{array}$ & $\begin{array}{l}\text { Integração } \\
\text { neural e } \\
\text { epigenética } \\
\text { contribuições } \\
\text { para os } \\
\text { sintomas do } \\
\text { transtorno de } \\
\text { estresse pós } \\
\text { traumático : } \\
\text { o papel do } \\
\text { volume do } \\
\text { hipocampo e } \\
\text { a metilação } \\
\text { do gene } \\
\text { glicocorticoid } \\
\text { es. }\end{array}$ & $\begin{array}{l}\text { Artigo de } \\
\text { Pesquisa }\end{array}$ & $\begin{array}{l}\text { O artigo procura } \\
\text { determinar se a } \\
\text { combinação de } \\
\text { imagens cerebrais } \\
\text { e epigenética é um } \\
\text { melhor } \\
\text { prognosticador da } \\
\text { sintomatologia do } \\
\text { TEPT do que } \\
\text { qualquer fator } \\
\text { isoladamente } \\
\text { Medindo o volume } \\
\text { do hipocampo e a } \\
\text { metilação } \\
\text { citosina. }\end{array}$ & $\begin{array}{l}\text { Os dados } \\
\text { revelaram uma } \\
\text { interação } \\
\text { significativa } \\
\text { entre } \\
\text { Metilação do } \\
\text { NR3C1e } \\
\text { tamanho do } \\
\text { hipocampo. As } \\
\text { descobertas } \\
\text { fortalecem a } \\
\text { ideia de que a } \\
\text { epigenética e a } \\
\text { anatomia } \\
\text { neural podem } \\
\text { ser usadas } \\
\text { como um } \\
\text { indicador } \\
\text { eficaz para o } \\
\text { TEPT }\end{array}$ \\
\hline $\begin{array}{l}\text { Schechter } \\
\text { D.S et al } \\
(2016)\end{array}$ & $\begin{array}{l}\text { Associação } \\
\text { da metilação } \\
\text { do receptor } \\
\text { de serotonina } \\
\text { 3A com } \\
\text { exposição à } \\
\text { violência } \\
\text { materna, } \\
\text { atividade } \\
\text { neural e }\end{array}$ & $\begin{array}{l}\text { Relatório de } \\
\text { Pesquisa }\end{array}$ & $\begin{array}{l}\text { O estudo em } \\
\text { questão examinou } \\
\text { se a metilação do } \\
\text { HTR3A pode estar } \\
\text { associada à } \\
\text { exposição da mãe } \\
\text { à violência } \\
\text { interpessoal (VPI), } \\
\text { à psicopatologia } \\
\text { relacionada à VPI, } \\
\text { à perturbação }\end{array}$ & $\begin{array}{l}\text { A frequência } \\
\text { de exposição à } \\
\text { VPI materna } \\
\text { foi associada } \\
\text { ao TEPT } \\
\text { materno; e o } \\
\text { TEPT-TEPT } \\
\text { materno, por } \\
\text { sua vez, } \\
\text { associou-se à } \\
\text { DSO infantil. }\end{array}$ \\
\hline
\end{tabular}




\begin{tabular}{|c|c|c|c|c|}
\hline & $\begin{array}{l}\text { agressão de } \\
\text { criança. }\end{array}$ & & $\begin{array}{l}\text { infantil do apego e } \\
\text { à atividade neural } \\
\text { materna. }\end{array}$ & \\
\hline $\begin{array}{l}\text { Perroud N } \\
\text { et al(2014) }\end{array}$ & $\begin{array}{l}\text { O genocídio } \\
\text { tutsi e a } \\
\text { transmissão } \\
\text { transgeracio } \\
\text { nal do } \\
\text { esforço } \\
\text { materno: } \\
\text { epigenética e } \\
\text { biologia do } \\
\text { eixo HPA. }\end{array}$ & $\begin{array}{l}\text { Artigo de } \\
\text { Pesquisa }\end{array}$ & $\begin{array}{lr}\text { O estudo da } \\
\text { transmissão do } \\
\text { transtorno de } \\
\text { estresse pós- } \\
\text { traumático parental } \\
\text { (TEPT) para a } \\
\text { prole que pode ser } \\
\text { explicada pela } \\
\text { transmissão de } \\
\text { processos } \\
\text { epigenéticos, } \\
\text { como o status de } \\
\text { metilação do gene } \\
\text { NR3C1 e o } \\
\text { receptor } \\
\text { glicocorticóide } \\
\text { (GR) }\end{array}$ & $\begin{array}{l}\text { Houve } \\
\text { correlação } \\
\text { significante } \\
\text { entre a } \\
\text { gravidade do } \\
\text { TEPT } \\
\text { depressão nas } \\
\text { mães e a } \\
\text { gravidade do } \\
\text { TEPT } \\
\text { depressão em } \\
\text { seus filhos, } \\
\text { respectivamen } \\
\text { te. }\end{array}$ \\
\hline $\begin{array}{l}\text { Paquette } \\
\text { A.G et al } \\
(2014)\end{array}$ & $\begin{array}{l}\text { Transtorno } \\
\text { de estresse } \\
\text { pós- } \\
\text { traumático } \\
\text { em pacientes } \\
\text { com } \\
\text { transtorno } \\
\text { bipolar: uma } \\
\text { revisão de } \\
\text { prevalência, } \\
\text { correlatos e }\end{array}$ & $\begin{array}{l}\text { Estudo } \\
\text { Coorte }\end{array}$ & $\begin{array}{l}\text { O estudo visa por } \\
\text { em teste a hipótese } \\
\text { de que a metilação } \\
\text { da FKBP5 } \\
\text { placentária e a } \\
\text { variação genética } \\
\text { contribuem para o } \\
\text { controle da } \\
\text { expressão gênica, } \\
\text { e estão associadas } \\
\text { aos desfechos do }\end{array}$ & $\begin{array}{l}\text { Os dados } \\
\text { mostram que } \\
\text { bebês com os } \\
\text { níveis mais } \\
\text { altos de } \\
\text { metilação } \\
\text { experimentaria } \\
\text { m uma } \\
\text { redução na } \\
\text { expressão de } \\
\text { FKBP5, }\end{array}$ \\
\hline
\end{tabular}




\begin{tabular}{|c|c|c|c|c|}
\hline & $\begin{array}{l}\text { estratégias } \\
\text { de } \\
\text { tratamento. }\end{array}$ & & $\begin{array}{l}\text { neurodesenvolvim } \\
\text { ento infantil. }\end{array}$ & $\begin{array}{l}\text { resultando no } \\
\text { aumento da } \\
\text { ativação do } \\
\text { cortisol em } \\
\text { receptores de } \\
\text { glicocorticóide } \\
\text { s dentro da } \\
\text { placenta, o que } \\
\text { pode } \\
\text { influenciar a } \\
\text { ativação da via } \\
\text { de resposta } \\
\text { dos } \\
\text { glicocorticóide } \\
\text { s no bebê em } \\
\text { desenvolvimen } \\
\text { to. }\end{array}$ \\
\hline $\begin{array}{l}\text { Lynn M. et } \\
\text { al (2016) }\end{array}$ & $\begin{array}{l}\text { Uma variante } \\
\text { de risco } \\
\text { identificada } \\
\text { em todo o } \\
\text { genoma para } \\
\text { o TEPT é um } \\
\text { locus de } \\
\text { característica } \\
\text { quantitativa } \\
\text { da metilação } \\
\text { e confere } \\
\text { ativação } \\
\text { cortical } \\
\text { diminuída e }\end{array}$ & $\begin{array}{l}\text { Estudo de } \\
\text { Coorte }\end{array}$ & $\begin{array}{l}\text { Neste estudo tem } \\
\text { por objetivo a } \\
\text { compreensão do } \\
\text { risco genético para } \\
\text { o TEPT. Foi } \\
\text { observado uma } \\
\text { amostra com um } \\
\text { desenho fenótipo } \\
\text { extremo e casos } \\
\text { controles com } \\
\text { exposições } \\
\text { semelhantes. }\end{array}$ & $\begin{array}{l}\text { A coorte } \\
\text { SBPBC teve } \\
\text { uma média } \\
\text { geral de } \\
\text { escores de } \\
\text { sintomas de } \\
\text { TEPT. No } \\
\text { entanto, como } \\
\text { a coorte foi } \\
\text { desenvolvida } \\
\text { com fenótipos } \\
\text { extremos, a } \\
\text { gravidade dos } \\
\text { sintomas foi }\end{array}$ \\
\hline
\end{tabular}




\begin{tabular}{|c|c|c|c|c|}
\hline & $\begin{array}{l}\text { as faces com } \\
\text { medo }\end{array}$ & & & $\begin{array}{l}\text { muito maior } \\
\text { nos casos de } \\
\text { TEPT. }\end{array}$ \\
\hline $\begin{array}{l}\text { Vukojevic } \\
\text { et al (2014) }\end{array}$ & $\begin{array}{l}\text { A } \\
\text { modificação } \\
\text { epigenética } \\
\text { do gene do } \\
\text { receptor } \\
\text { glicocorticóid } \\
\text { e está } \\
\text { vinculada à } \\
\text { memória } \\
\text { traumática e } \\
\text { ao risco de } \\
\text { tensão de } \\
\text { stress pós- } \\
\text { traumático } \\
\text { em } \\
\text { sobrevivente } \\
\text { s de } \\
\text { genocídio. }\end{array}$ & $\begin{array}{l}\text { Comportamen } \\
\text { tal/ Cognitivo }\end{array}$ & 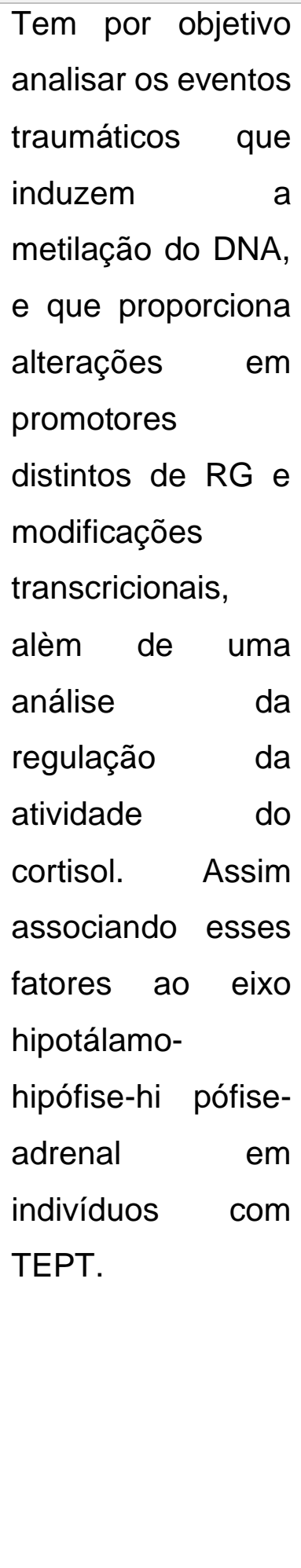 & $\begin{array}{l}\text { A análise } \\
\text { também } \\
\text { revelou um } \\
\text { efeito principal } \\
\text { do tempo de } \\
\text { amostragem } \\
\text { de cortisol. } \\
\text { Testes parciais } \\
\text { indicaram que } \\
\text { os níveis de } \\
\text { cortisol foram } \\
\text { significativame } \\
\text { nte menores } \\
\text { no grupo TEPT } \\
\text { em } \\
\text { comparação } \\
\text { com o grupo } \\
\text { controle para o } \\
\text { intervalo de } \\
\text { tempo entre } 30 \\
\text { e } 45 \text { minutos } \\
\text { após } \\
\text { despertar } \\
\text { entre } 45 \text { e } 60 \\
\text { minutos após o } \\
\text { desperta, } \\
\text { glicocorticóide }\end{array}$ \\
\hline
\end{tabular}




\begin{tabular}{|c|c|c|c|c|}
\hline & & & & $\begin{array}{l}\text { s foram } \\
\text { significativame } \\
\text { nte menores } \\
\text { no TEPT, em } \\
\text { comparação } \\
\text { ao outro grupo } \\
\text { de } \\
\text { comparação.) }\end{array}$ \\
\hline $\begin{array}{l}\text { Kaminsky } \\
Z \text { et al( } \\
2015)\end{array}$ & $\begin{array}{l}\text { Variação } \\
\text { epigenética e } \\
\text { genética no } \\
\text { comportame } \\
\text { nto suicida } \\
\text { predicado de } \\
\text { ska2 } \\
\text { transtorno de } \\
\text { estresse pós- } \\
\text { traumático. }\end{array}$ & Artigo Original & $\begin{array}{l}\text { O objetivo foi } \\
\text { investigar a } \\
\text { interação do SKA2 } \\
\text { e exposição ao } \\
\text { trauma na função } \\
\text { do eixo HPA, } \\
\text { tentativa de } \\
\text { suicídio e TEPT }\end{array}$ & $\begin{array}{l}\text { Foi observado } \\
\text { que } \\
\text { biomarcador } \\
\text { epigenético e } \\
\text { genético, } \\
\text { SKA2, previu } \\
\text { casos de TEPT } \\
\text { em civis } \\
\text { quando o } \\
\text { abuso infantil } \\
\text { foi incorporado }\end{array}$ \\
\hline $\begin{array}{l}\text { MULLIGAN } \\
\text { C.J. et al } \\
(2012)\end{array}$ & $\begin{array}{l}\text { Metilação no } \\
\text { NR3C1 em } \\
\text { recém- } \\
\text { nascidos } \\
\text { associar com } \\
\text { a exposição } \\
\text { ao estresse } \\
\text { pré-natal } \\
\text { materna e o } \\
\text { peso do } \\
\text { recém- } \\
\text { nascido }\end{array}$ & $\begin{array}{l}\text { Artigo } \\
\text { Integrado }\end{array}$ & $\begin{array}{l}\text { O estudo tem } \\
\text { como objetivo } \\
\text { testar a ideia de } \\
\text { que estressores } \\
\text { psicossociais } \\
\text { maternos extremos } \\
\text { como observado } \\
\text { na República } \\
\text { Democrática do } \\
\text { Congo podem } \\
\text { modificar marcas } \\
\text { epigenéticas de }\end{array}$ & $\begin{array}{l}\text { Concluiu que o } \\
\text { aumento da } \\
\text { metilação pode } \\
\text { restringir a } \\
\text { maleabilidade } \\
\text { da expressão } \\
\text { gênica a } \\
\text { restringir a } \\
\text { gama de } \\
\text { possíveis } \\
\text { respostas de } \\
\text { adaptação ao }\end{array}$ \\
\hline
\end{tabular}




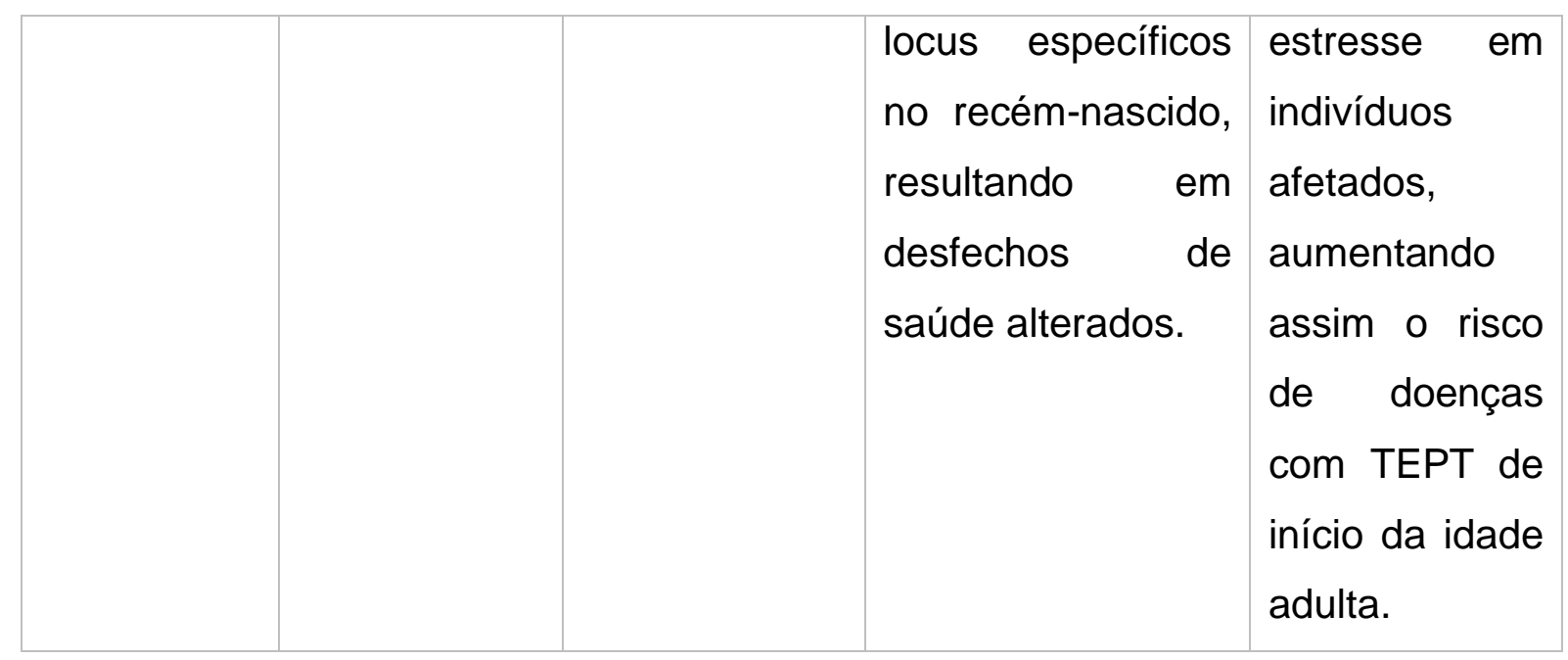

Fonte: Autores da pesquisa (2019).

\section{RESULTADOS E DISCUSSÃO}

\subsection{HIPERMETILAÇÃO, HIPOMETILAÇÃO E O TEPT}

O processo de metilação exerce funções fundamentais no desenvolvimento embrionário, inativação do cromossomo $X$, regulação gênica, imprinting genômico e modificações da cromatina. Porém, há dois mecanismos de regulação da expressão de gene dentro do processo de metilação: a hipermetilação e a hipometilação. Comumente, a hipometilação do DNA causa um aumento na expressão gênica, porém a hipermetilação diminui a expressão dos genes determinados (VUKOJEVIC, 2014).

Naturalmente, os padrões de metilação do genoma mudam com o chegar da senescência. Majoritariamente, ocorre uma hipometilação concomitante com a hipermetilação de algumas ilhas CpG distribuídas em sequências recorrentes, como também em genes transcricionalmente importantes. Alterações epigenéticas estão diretamente relacionadas ao avanço da idade, contribuindo com vários transtornos ou doenças adquiridas (FRAGA et al., 2005).

A exposição repetida a um estresse durante a infância predispõe uma reação neurobiológica que se mantém por toda a vida do indivíduo, podendo acometer negativamente a saúde psíquica. Estudos anteriores demonstram efetivamente que 
os estressores ambientais, não apenas no início da vida, mas também durante a gravidez, aumentam estado de metilação do éxon 1F do gene NR3C1. No cérebro, o hipocampo é uma área abundante em RGs, que também expressa o promotor NR3C1-1F. Além disso, há registros que o hipocampo é sensível à tensão em um nível bioquímico e estrutural. Por isso, a metilação do DNA tem sido associada a alterações na densidade de RG no hipocampo, após a exposição ao estresse ambiental. Por conseguinte, estudos apontam que, seja por exposição ao estresse e eventual perda de volume do hipocampo ou pelo estado de hipometilação inato combinado com um volume do hipocampo inferior são capazes de predispor um indivíduo ao TEPT (MCNERNEY et al., 2018).

Não se pode afirmar que o TEPT é associado ao volume do hipocampo. Embora essa controvérsia possa ser justificada por que nem todas as variáveis importantes envolvidas nos volumes do hipocampo e o TEPT, foram completamente consideradas, como o mecanismo de metilação do DNA (PERROUD et al., 2014).

A realização da hipermetilação é capaz de perturbar efetivamente o equilíbrio do eixo HPA, o que explica como os níveis de cortisol (YEHUDA et al., 2009) alterados são encontrados nos filhos de sobreviventes de desastres diagnosticados com TEPT. Assim, a epigenética consegue fornecer informações importantes sobre a fisiopatologia da TEPT, possibilitando entender como ocorre a transmissão transgeracional desse transtorno (PERROUD et al., 2014); (JURUENA et al., 2004).

Alteração epigenética no portador de TEPT e propagação para sua prole.

Essa alteração epigenética tem relação direta com o eixo HPA, que é responsável basicamente pela regulação neuroendócrina dos processos fisiológicos. Contudo, para uma pessoa com TEPT, o funcionamento desse eixo se altera como uma forma de adaptação que pode ser relacionada aos baixos níveis de cortisol. Por isso, vários estudos sugerem que esse processo está ligado ao início do desenvolvimento de doenças psíquicas, e provavelmente tem seu surgimento desde o útero, por consequência do reflexo da programação dos glicocorticoides por meio da epigenética (BRAND et al., 2006). 
Estes estudos apontam que o aumento da metilação do gene NR3C1, responsável pela codificação de RG, ocasiona o desequilíbrio do MR - codificado pelo gene NR3C2 - resultando essencialmente na redução da disponibilidade de RG proporcionando maior suscetibilidade desse indivíduo à doenças psiquiátricas relacionadas ao estresse, tais como depressão e TEPT (BRAND et al., 2006; MULLIGAN et al., 2012)

Somado a esse fator de alteração da estrutura no DNA das pessoas que sofrem interferência de estressores externos, vários estudos sugerem que o TEPT é um forte correlato para o desenvolvimento dessa mesma patologia nas gerações futuras (ROBERTS et al., 2012). A propagação transgeracional é associada à transmissão de alterações biológicas adaptativas no eixo HPA. O TEPT causa a alteração do equilíbrio neuroendócrino do eixo HPA, principalmente quando se trata da secreção de baixos níveis de cortisol e essa baixa secreção é aumentada também por medicamentos anti-inflamatórios que fazem parte do grupo dos corticosteroides que inibem a produção do cortisol pelo corpo, potencializando igualmente sua baixa secreção que eleva, consequentemente, a probabilidade da prole dos progenitores com TEPT adquirirem futuramente a doença (BRAND et al., 2006), (LABONTÉ et al., 2014). O baixo nível de cortisol em relação à TEPT parental parece estar presente no início desenvolvimento do bebê - provavelmente desde o útero-, uma vez que causam a reprogramação dos RGs por meio de alterações epigenéticas que propiciam o aparecimento de distúrbios na expressão genética (RADTKE et al., 2011). A resposta fetal ao nível de cortisol indica que a exposição ao estresse gestacional materno tem impactos duradouros no desenvolvimento dessa criança por meio do aumento na metilação do gene promotor de RG que persiste além da infância (RADTKE et al., 2011), (LABONTÉ et al., 2014). Isto representa a programação adaptativa fetal do eixo HPA, que pode ser responsável por problemas psicológicos posteriores, como depressão ou TEPT. Nessa perspectiva, o feto exposto aos níveis alterados de cortisol na circulação materna associa-se com problemas neurológicos e de desenvolvimento da próxima geração (BRAND et al., 2006).

A placenta, órgão central do desenvolvimento fetal, regula a exposição e retroalimentação à sinalização materna, alterando o ambiente de desenvolvimento 
fetal. Os mecanismos epigenéticos, como a metilação do DNA, quando ocorrem em regiões reguladoras, alteram a função da placenta, modificando a transcrição gênica ou o potencial de transcrição (PAQUETTE et al., 2014). A FKBP5 (proteína de ligação FK506) diminui a sensibilidade do $R G$ e impede a translocação nuclear que consequentemente reduz à capacidade responsiva a liberação de cortisol (KAMINSKY et al., 2015). A metilação do FKBP5 dentro da região reguladora no íntron 7 é associada modificações neurológicas. Observou-se que o íntron 7 se liga ao local de início da transcrição de FKBP5 e a metilação altera a indução do FKBP5. Em uma linhagem celular do hipocampo humano, o cortisol induz a desmetilação desta região reguladora dentro do íntron 7 durante períodos críticos de diferenciação e proliferação celular. O polimorfismo do FKBP5 também está ligado à indução alterada de RNAm, que determina mudanças no tamanho do hipocampo, bem como a doenças relacionadas a alterações no eixo HPA como o TEPT (SCHECHTER et al., 2016); (KAMINSKY et al., 2015).

Estudos demonstram que o feto com o gene localizado no íntron 7 hipermetilado experimentaria uma redução na expressão do FKBP5, resultando uma maior sensibilidade dos RGs ao cortisol proveniente da circulação materna dentro da placenta, influenciando, desse modo, o desenvolvimento fetal. Estudos anteriores ao biomarcador FKBP5 observaram associações com TEPT que são caracterizadas pelo comportamento hipervigilante e hiperexcitado. Portanto, as alterações no FKBP5 diminuem a resposta ao cortisol influenciam o comportamento promovendo uma resposta hipervigilante. Indivíduos com maior metilação do FKBP5 no útero tem uma via de resposta de cortisol pouco ativa no momento do nascimento, tornando-se predispostos a desenvolver distúrbios relacionados à hiperresponsividade do eixo HPA, como TEPT ou ansiedade (KAMINSKY et al., 2015). Em seguida, foi analisado que esse biomarcador possui sua relevância funcional para um controle epigenético ainda desconhecido e pode alterar o desenvolvimento fetal, em especial no desenvolvimento neurocomportamental. Desse modo, os estudos demonstram efetivamente que os estressores externos, afetam de forma ativa durante a gravidez, causam hipermetilação do éxon $1 \mathrm{~F}$ do gene $\mathrm{NR} 3 \mathrm{C} 1$ e a região do promotor de $\mathrm{RG}$ de forma a interferir significativamente na fase adulta (RADTKE et al., 2011) 
Este fenômeno é relevante por modificar de forma prolongada o equilíbrio do eixo HPA e alterar os níveis de cortisol encontrados nos filhos das vítimas de desastres naturais ou antropogênicos que foram diagnosticados com TEPT. Assim, a epigenética pode fornecer informações sobre o comportamento dos biomarcadores e as manifestações macroestruturais de forma a clarificar a transmissão transgeracional desse transtorno.

Figura 03. Metilação de DNA- Os pares de bases formam o DNA. Estes pares se entrelaçam nas proteínas chamadas de histonas. Essa estrutura semelhante a um "colar de pérolas" que forma a cromatina. A metilação é o principal mecanismo epigenético.

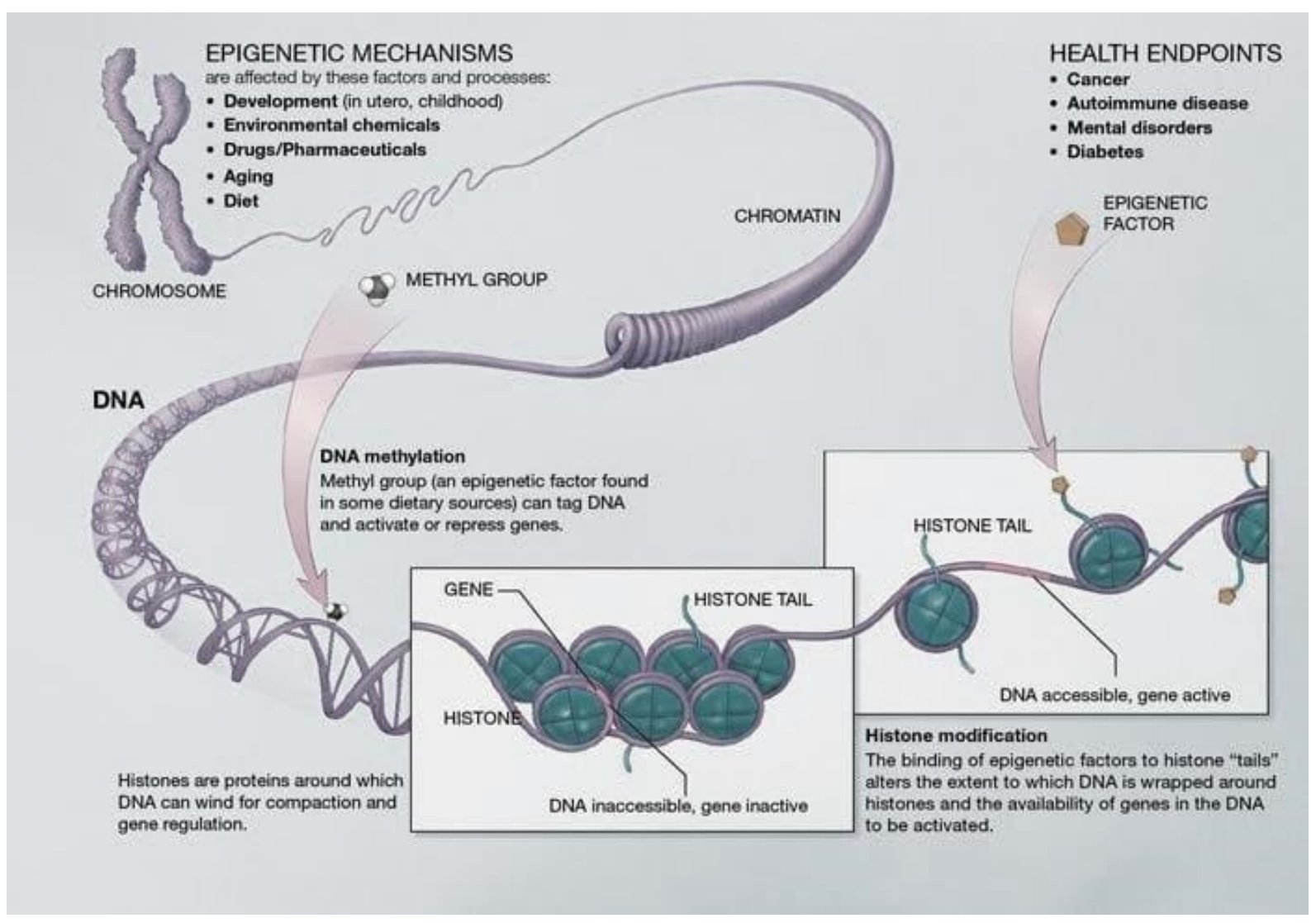

Fonte: Site Ciências e Cognição. 


\subsection{O PAPEL DA ALTERAÇÃO EPIGENÉTICA NO VOLUME DO HIPOCAMPO E NO RECEPTOR DE GLICOCORTICÓIDE}

Atualmente, correlaciona-se a metilação do gene NR3C1 com o volume do hipocampo e a depressão. O hipocampo é sensível ao estresse e altamente responsivo a metilação deste biomarcador. Relacionando esses fatores à neuroimagem e aos mecanismos epigenéticos, foram usados para fornecer a base para uma interessante orientação na pesquisa ligada ao TEPT e às alterações no genótipo. De forma geral, o TEPT revelou uma resposta negativa entre NR3C1 e tamanho do hipocampo. Além disso, uma forte relação entre esse biomarcador, o hipocampo, RGs e a resposta ao TEPT. Especificamente, o hipocampo regula a atividade do eixo HPA e por consequência a ação dos glicocorticóides, como o cortisol. Aumentando, então, os sinais de estresse no corpo de forma significativa (PERROUD et al.,2014), (AMLI et al., 2016).

Isso nos levaria a esperar que os valores mais baixos de metilação estão associados a um hipocampo de tamanho menor, que os veteranos de guerra que provavelmente não têm TEPT deveriam ter. No entanto, o TEPT é associado a uma hipometilação no geral e é verificado que esta relação se perde porque os valores mais baixos de metilação também podem ocorrer, independentemente do tamanho do hipocampo. Pesquisas futuras devem ser realizadas para determinar se essa tendência permanece a mesma em indivíduos saudáveis, outros grupos de veteranos ou civis com TEPT e em pacientes com outros transtornos psiquiátricos (AMLI et al., 2016).

A relação entre o volume do hipocampo e o TEPT é atualmente controversa na literatura. Estudos de imagem apontam que veteranos de guerra com TEPT póscombate têm um volume do hipocampo menor em comparação a veteranos sem TEPT. Contudo, outros estudos não conseguiram replicar essa relação. A razão provável dessa inconsistência nos resultados deve-se ao fato de que o TEPT é um transtorno multifatorial (AMLI et al., 2016), (LABONTÉ et al., 2014). Por conseguinte, compreender as bases biológicas desse transtorno requer mais do que apenas a neuroimagem para analisar a relação do TEPT com volume e funcionamento do 
hipocampo. Por isso é imperativo integrar o conhecimento de imaginologia, bioquímica e epigenética no intuito de aprofundar o conhecimento atual sobre esse transtorno.

\section{CONSIDERAÇÕES FINAIS}

Neste artigo, após estudo dos biomarcadores citados que são expressos ou não por mudanças epigenéticas, pode-se pontuar alguns dos resultados mais atuais em pesquisas sobre o TEPT e acompanhar como esses artigos fornecem interessantes e variadas perspectivas para a descoberta prematura da predisposição para determinados transtornos psicológicos. Apesar de os artigos não serem conclusivos, os resultados de seus estudos indicam que os acontecimentos traumáticos no TEPT na macroestrutura corporal são justificados através das alterações de metilação de DNA que modificam a expressão do gene e, consequentemente, a atividade do eixo HPA. Por isso, o TEPT não só produz mudanças no eixo de controle neuroendócrino do corpo como também modificações podem ser propagadas às gerações futuras que alteram o mecanismo da prole para atuar e modo semelhante com o mecanismo de seu progenitor.

Embora a gama de informações sobre o tema abordado tenha sido ampla, alguns artigos estudados revelaram a necessidade de mais pesquisas para obter um maior aprofundamento sobre o assunto. Assim, seria possível consolidar as informações obtidas nos estudos supracitados.

\section{REFERÊNCIAS}

AMLI, Lynn M. et al. A Genome-Wide Identified Risk Variant for PTSD is a Methylation Quantitative Trait Locus and Confers Decreased Cortical Activation to Fearful Faces. Am J Med Genet B Neuropsychiatr Genet. Georgia, p. 327-336. 18 maio 2018. Disponível em: <https://www.ncbi.nlm.nih.gov/pmc/articles/PMC4844461/>. Acesso em: 22/11/ 2019.

BRAND, Sarah R. et al. The effect of maternal PTSD following in utero trauma exposure on behavior and temperament in the 9-month-old infant. Annals of the New 
York Academy of Science. Nova lorque, p. 454-458. abr. 2006. Disponível em: $<$ https://nyaspubs.onlinelibrary.wiley.com/doi/full/10.1196/annals.1364.041>. Acesso em: 30/10/2019.

COSTA, Everton de Brito Oliveira; PACHECO, Cristiane. Epigenetics: gene expression regulation at transcriptional level and its implications. Semina. Londrina, p. 125-136. dez. 2013. Disponível em: <http://www.uel.br/revistas/uel/index.php/seminabio/article/viewFile/5142/13877>. Acesso em: 01 fev. 2019

FRAGA, Mario F. et al. Epigenetic differences arise during the lifetime of monozygotic twins. Epigenetics Differences Arise During The Lifetime Of Monozygotic Twins. Proceedings Of The Proceedings Of The National Academy Of Sciences Of The United States Of America. Seattle, p. 106-117. 17 jan. 2005. Disponível em: <https://www.pnas.org/content/102/30/10604.long >. Acesso em: 27/10/2019.

HARRIS, Angela P. et al. Mineralocorticoid and glucocorticoid receptor balance in control of HPA axis and behaviour. Psychoneuroendocrinology. Edimburgo, p. 648658. maio 2013. Disponível em: <https://www.sciencedirect.com/science/article/pii/S0306453012002983?via\%3Dihub >. Acesso em: 11/09/2019

https://www.tandfonline.com/doi/abs/10.3109/15622975.2013.866693?journalCode=i wbp20. Acesso em: 7 ago. 2019.

JURUENA, Mario F; CLEARE, Anthony J; PARIANTE, Carmine M. The Hypothalamic Pituitary Adrenal axis, Glucocorticoid receptor function and relevance to depression. Rev. Bras. Psiquiatr. São Paulo, v. 26, n. 3, p. 189-201, Setembro 2004.

em:

$<$ http://www.scielo.br/scielo.php?script=sci_arttext\&pid=S1516-

44462004000300009\&Ing=en\&nrm=iso >. Acesso em: 22/11/2019.

KAMINSKY, Z et al. Epigenetic and genetic variation at SKA2 predict suicidal behavior and post-traumatic stress disorder. Translational Psychiatry. Baltimore, p. 627-639. 
ago.

2015.

Disponível

em:

<https://www.ncbi.nlm.nih.gov/pmc/articles/PMC4564560/>. Acesso em: 20/11/2019.

LABONTÉ, Benoit et al. Epigenetic modulation of glucocorticoid receptors in posttraumatic stress disorder. Translational Psychiatry. Montreal, p. 368-381. abr. 2014. Disponível em: <https://www.nature.com/articles/tp20143>. Acesso em: 31/10/2019.

MCNERNEY, M. Windy et al. Integration of neural and epigenetic contributions to posttraumatic stress symptoms: The role of hippocampal volume and glucocorticoid receptor gene methylation. Plos One. California, p. 421-434. 07 fev. 2018. Disponível em: $\quad<$ https://journals. plos.org/plosone/article?id=10.1371/journal.pone.0192222>. Acesso em: 10 dez. 2019.

MULLIGAN, Connie et al. Methylation changes at NR3C1 in newborns associate with maternal prenatal stress exposure and newborn birth weight. Epigenetics. Florida, p. 853-857. jul. 2012. Disponível em: <https://www.tandfonline.com/doi/abs/10.4161/epi.21180>. Acesso em: 08/12/2019.

NEUGEBAUER, Richard et al. Post-traumatic stress reactions among Rwandan children and adolescents in the early aftermath of genocide. International Journal Of Epidemiology. Nova lorque, p. 1033-1045. ago. 2009. Disponível em: <https://academic.oup.com/ije/article/38/4/1033/849053>. Acesso em: 20 /12/ 2019.

PAQUETTE, Alison $G$. et al. Placental FKBP5 genetic and epigenetic variation is associated with infant neurobehavioral outcomes in the RICHS cohort. Plos One. New Hampshire, 12 ago. 2014. p. 133-143. Disponível em: <https://www.ncbi.nlm.nih.gov/pubmed/25115650>. Acesso em: 20 out. 2019.

PERROUD, Nader et al. The Tutsi genocide and transgenerational transmission of maternal stress: epigenetics and biology of the HPA axis. The World Journal Of Biological Psychiatry. Genebra, 01 abr. 2014. p. 334-345. Disponível em: 
RADTKE, Karl M. et al. Transgenerational impact of intimate partner violence on methylation in the promoter of the glucocorticoid receptor. Translational Psychiatry. Konstanz, p. 456-470. jul. 2011. Disponível em: <https://www.ncbi.nlm.nih.gov/pmc/articles/PMC3309516/>. Acesso em: 20/10/2018

ROBERTS, Andrea $L$ et al. Posttraumatic stress disorder across two generations: concordance and mechanisms in a population-based sample. Biol Psychiatry. Massachussetts, p. 505-511. abr. 2012. Disponível em: <https://www.ncbi.nlm.nih.gov/pmc/articles/PMC3412195/>. Acesso em: 21/09/2019.

SCHECHTER, Daniel S. et al. The association of serotonin receptor $3 \mathrm{~A}$ methylation with maternal violence exposure, neural activity, and child aggression. Behavioural Brain Research. Genebra, p. 268-277. 15 maio 2017. Disponível em: <https://www.sciencedirect.com/science/article/pii/S0166432816307720?via\%3Dihub >. Acesso em: 20 out. 2019.

VUKOJEVIC, Vanja et al. Epigenetic Modification of the Glucocorticoid Receptor Gene Is Linked to Traumatic Memory and Post-Traumatic Stress Disorder Risk in Genocide Survivors. The Journal Of Neuroscience. Suiça, p. 10274-10284. 30 de julho 2014. Disponível em: http://www.jneurosci.org/content/34/31/10274.long. Acesso em: 02 nov. 2019.

YEHUDA, Rachel; BIERER, Linda M. Transgenerational transmission of cortisol and PTSD risk. Progress In Brain Research. Nova lorque, p. 121-135. nov. 2007. Disponível em: $<$ https://www.sciencedirect.com/science/article/pii/S0079612307670095?via\%3Dihub >. Acesso em: 19/11/2019.

Enviado: Janeiro, 2020.

Aprovado: Agosto, 2020. 